\section{UK university rankings}

SIR-W. I. Montgomery has recently proposed (Nature 341,$562 ; 1989$ ) that there is a negative correlation between the research grades allocated to universities by the Universities Funding Council (UFC) and the teaching quality as inferred from the percentage of graduates unemployed or in short-term work. The latter statistics were published by the Financial Times (FT) on 13 September 1989. There are a number of weaknesses in this analysis.

First, it is proposed to omit, on the one hand, Oxford and Cambridge, "which are exceptional in terms of research performance and whose graduates are moderately successful in avoiding the dole queues", and on the other hand Ulster and Keele "where research and teaching both fare badly using the present criteria". I submit that the proposed omission without good reason of four out of 45 universities because they are patent outliers for the hypothesis being tested is playing skittles with statistics.

Second, some universities or colleges are included in one table but not in the other. Montgomery does not explain fully what he has done with these cases.

Third, substantial number of graduates (3.1-15.7 per cent per institution) could not be traced in the $F T$ survey and students who read for degrees for personal interest and satisfaction rather than with the intention of using the qualification to obtain employment are included in the unemployed. The FT questions whether students should be accepted by universities if they do not intend to work after graduation. That is another problem, but the method of presentation of the survey by the $F T$ probably gives a distorted reflection of the views held by potential employers concerning the quality of graduates of a particular university.

Fourth, some institutions (for example, Brunel, Salford and Aston) are mainly geared to teaching and research in pure and especially applied sciences. Not surprisingly, the percentage of students of these institutions who find employment quickly is greater than in the case of universities offering a broader range of academic disciplines. While bank interest rates remain high, it is understandable if employers tend to focus their attention more sharply on graduates with the most immediately pertinent qualification rather than possibly better graduates in less relevant disciplines.

Finally, students in Northern Ireland in particular, but also in parts of Scotland and Wales, tend to want to stay in a familiar environment in preference to migrating to those parts of the United Kingdom where unemployment is lower and graduates are in greater demand. This may partially explain the low position of
Ulster, St Andrews, Edinburgh and Wales in the $F T$ graduate employment survey.

The other variable in the analysis, the UFC research grading, is also not free from criticism. The grading allocated to a university department is partly a function of external research money acquired. It is well known that the research councils have been able to fund only a small percentage of alpharated research applications. The remainder, whether rated alpha, beta or rejected as unsound, do not affect the UFC grading, to the best of my knowledge. In other words, there are good research ideas emanating from many institutions that are not funded because of shortage of money and one may conclude that UFC gradings are influenced to some extent by government policy towards funding of scientific research in universities.

In summary, an attempt to establish a correlation between two parameters, one of which is seriously flawed quantitatively while the other is influenced by economic and political factors in addition to academic factors, is not a fruitful exercise. Montgomery's last sentence is an open invitation to government, should this be felt necessary, to downgrade some departments or even universities unjustifiably to a teaching role only.

\section{Clover Place,}

D.T. ELMORE

Eynsham,

Oxon OX8 1QL, UK

\section{Sri Lankan death}

SIR-We were saddened to receive the news of the death of a close colleague, $\mathrm{Dr}$ Rajani Thiranagama of the University of Jaffna, Sri Lanka. She was shot dead by an unidentified gunman on 21 September when returning to her house after teaching in the Medical School where she was head of the department of anatomy.

Thiranagama was a prominent member of University Teachers for Human Rights (UTHR), a monitoring organization based at the Universities of Colombo and Jaffna. She had been active in compiling and circulating several reports documenting human rights violations by militant opposition groups, as well as the Indian armed forces who control the north and east of Sri Lanka. She had been harassed and threatened repeatedly since the contents of these reports, which included evidence of killings, became known.

Thiranagama has close links with the University of Liverpool, where she obtained her $\mathrm{PhD}$ in 1986. She paid

Letters submitted for Correspondence should be typed, double-spaced, on one side of the paper only. annual study visits to our department, and was highly regarded by all who knew her. Rajani's friends and colleagues in Britain are writing letters to the Sri Lankan and Indian authorities, appealing for an independent inquiry into the circumstances surrounding her death. We hope that individuals and institutions in other countries will add their weight to our appeal, especially since other Sri Lankan academics who are members of UTHR are now clearly at risk.

Letters may be sent to the ViceChancellor, University of Jaffna, Thirunelvely, Jaffna, Sri Lanka, who will forward them to the appropriate authorities. Further information about the campaign may be obtained from A.T.C., who may be contacted by electronic mail on MJ02 @UK.AC.LIVERPOOL.

\section{A. T. Chamberlain} B. A. WOOD

Department of Human Anatomy

and Cell Biology,

University of Liverpool,

PO Box 147 ,

Liverpool L69, 3BX, UK

\section{Journal reviewers}

SIR-We disagree with David R. Hershey (Nature 340, 424; 1989), who suggests that reviewers have no incentive to do an excellent job because they receive no pay, no recognition and no blame for a poor review. We believe that the satisfaction of participating in this important and traditional process is a significant incentive. We agree with Hershey that further incentives are justified.

Journal reviewers unselfishly donate their professional time to assist an editor in the decision whether a manuscript should be accepted, revised or rejected. The task of reviewing a paper may take several days. As such, consideration should be given to renumerating reviewers. Who, however, can afford to reimburse a reviewer even for a fraction of the time spent in this important work?

Editors should continue to publish the names of their reviewers in the journal. We suggest that journal editors should also write a letter of thanks to a reviewer together with a brief note about the quality of the review. Reviewers may then submit the letter along with their curriculum vitae to their department head when decisions concerning academic appointments, advancement and salary are to be made. Department heads should regard participation as a journal reviewer as an important aspect of an academician's curriculum vitae.

ALEXANDER K. C. LEUnG W. LANE M. ROBSON

Department of Pediatrics,

University of Calgary,

Alberta Children's Hospital,

Calgary, Alberta, Canada T2T 5C7 